\title{
Evaluation of flurbiprofen in detrusor instability
}

\author{
LINDA D CARDOZO，STUART L STANTON, HEATHER ROBINSON, DAVID HOLE
}

\section{Summary and conclusions}

Thirty women with detrusor instability ( 27 cases idiopathic, and three secondary to multiple sclerosis) completed a double-blind, cross-over trial of the prostaglandin synthetase inhibitor flurbiprofen and a placebo, results being evaluated by questionnaire and cystometry. Frequency, urgency, and urge incontinence were all significantly reduced with flurbiprofen $(P<0.001$, $P<0.025$, and $P<0.025$ respectively), as was the detrusorpressure rise during bladder filling $(P<0.01)$. Side effects, however, occurred in 13 patients while taking flurbiprofen compared with five while taking placebo $(P<0.025)$. After the trial 19 patients wished to continue with flurbiprofen.

Flurbiprofen is a useful treatment for idiopathic detrusor instability and is well tolerated by most patients.

\section{Introduction}

The role of prostaglandins in lower urinary tract function remains uncertain. Gilmore and Vane ${ }^{1}$ detected prostaglandinlike substances in blood samples from the vesical veins of dogs undergoing bladder distension. Prostaglandins (PG) $E_{1}, E_{2}, F_{1 \alpha}$, and $F_{2 \alpha}$ all produce contraction of human bladder muscle in vitro, $\mathrm{PGF}_{2 \alpha}$ being the most potent. ${ }^{2}$ Bultitude et $a l^{3}$ also showed that detrusor muscle strips from various animals contract under the influence of $\mathrm{PGE}_{2}$ and $\mathrm{PGF}_{2 \alpha}$ and concluded that prostaglandins are naturally produced by the detrusor and increase tone and spontaneous activity. At the seventh annual meeting of the International Continence Society in 1977 they reported giving $\mathrm{PGE}_{2}$ intravesically to 21 women with retention of urine and claimed subjective and objective improvement in 14 . There were no corroborative reports, however, and it seems doubtful whether the large prostaglandin molecule would pass through the bladder mucosa.

Aspirin-like drugs, particularly indomethacin, inhibit the synthesis of prostaglandins. ${ }^{4}$ Thus patients with diurnal and nocturnal frequency of micturition due to detrusor instability have obtained great relief from indomethacin. ${ }^{5}$ Nevertheless, oral treatment with $100 \mathrm{mg}$ twice daily produced headache and nausea in $59 \%$ of cases.

With the potency of aspirin being taken as unity, flurbiprofen in vitro reportedly has a relative molar potency of 5610 for $50^{\circ}$ inhibition of $\mathrm{PGE}_{2}$ synthesis, whereas that of indomethacin is $257 .{ }^{6}$ Flurbiprofen is used in rheumatoid arthritis and is well tolerated by most patients. ${ }^{7}$ We have therefore tested this drug in patients with detrusor instability.

\section{Patients and methods}

Thirty-five women diagnosed by videocystourethrography ${ }^{8}$ or subtracted cystometry as having detrusor instability (idiopathic or

Urodynamic Unit, Department of Obstetrics and Gynaecology, St George's Hospital Medical School, London SW17 ORE

LINDA D CARDOZO, MD, clinical research fellow (now registrar, department of obstetrics and gynaecology, King's College Hospital Group, London)

STUART L STANTON, FRCS, MRCOG, honorary senior lecturer

HEATHER ROBINSON, BSC, SRN, research sister

DAVID HOLE, BSC, MIBIOL, senior technician secondary to multiple sclerosis) were admitted to the trial. An increase in detrusor pressure exceeding $15 \mathrm{~cm}$ of water during bladder filling or provocative testing was taken as diagnostic. Organic bladder disease and neuropathy were sought by cystoscopy and neurological examination respectively.

The trial had a double-blind, cross-over design and compared flurbiprofen $50 \mathrm{mg}$ thrice daily with placebo that looked and tasted identical. The randomisation code was held by the pharmacy. Patients took each preparation for two weeks with one tablet-free week in-between. Cystometry was performed before entry to the trial and on the last day of each course. At each visit a questionnaire was completed by the doctor, recording symptoms and any side effects encountered. Throughout the trial each patient kept a 24-hour diary recording the number of times she voided during the day and night, the number of "urges" to void, and any episodes of incontinence. The diaries were presented whenever the patient attended for cystometry. A midstream specimen of urine was sent for culture and sensitivity testing before entry to the trial and after cystometry.

"Frequency" is defined here as the passage of urine seven or more times during the day and twice or more at night, and "severe" urgency and urge incontinence refers to symptoms causing a change in life style.

Statistical evaluation was by Student's $t$ test for paired data and McNemar's test as appropriate.

\section{Results}

Thirty women aged $21-74$ years (mean $49 \cdot 4$ ) completed the trial; 27 had idiopathic detrusor instability and three detrusor instability secondary to multiple sclerosis.

Table I gives the prevalence of symptoms before treatment, after flurbiprofen, and after placebo. The mean numbers of voidings during the day and night were 13.8 and 2.7 respectively before treatment, 8.7 and 1.4 after flurbiprofen, and 10.7 and 2.1 after placebo.

Table II shows the cystometric changes after treatment. Six patients were symptomatically completely cured by flurbiprofen and showed normal urodynamic values while taking the drug; all of them, however, had symptoms of detrusor instability and abnormal cystometrograms while taking placebo. The volume at which detrusor pressure rose above $15 \mathrm{~cm}$ of water was calculated from the cystometrograms: mean values before treatment, while taking flurbiprofen, and while taking placebo were 281,353 , and $303 \mathrm{ml}$ respectively.

Side effects occurred in 13 patients during the flurbiprofen period

TABLE I-Prevalence of symptoms before and after treatment. Figures are numbers of patients (percentages in parentheses)

\begin{tabular}{|c|c|c|c|c|}
\hline & & $\begin{array}{c}\text { Before } \\
\text { treatment }\end{array}$ & $\begin{array}{c}\text { After } \\
\text { flurbiprofen }\end{array}$ & $\begin{array}{c}\text { After } \\
\text { placebo }\end{array}$ \\
\hline $\begin{array}{l}\text { Frequency }\left\{\begin{array}{l}\text { Diurnal } \\
\text { Nocturnal }\end{array}\right. \\
\text { Urgency }\left\{\begin{array}{l}\text { Total } \ldots \\
\text { Severe } \ldots\end{array}\right. \\
\text { Urge } \\
\text { incontinence }\left\{\begin{array}{l}\text { Total } \\
\text { Severe }\end{array}\right. \\
\text { Stress incontinence } \\
\text { Enuresis .. .. }\end{array}$ & $\begin{array}{l}\cdots \\
\because \\
\because \\
\cdots \\
\cdots \\
\cdots\end{array}$ & $\begin{array}{l}29(97) \\
23(77) \\
30(100) \\
25(83) \\
29(97) \\
24(80) \\
15(50) \\
5(17)\end{array}$ & $\begin{array}{l}22(73) \\
11(37) \\
21(70) \\
6(20) \\
13(43) \\
3(10) \\
8(27) \\
2(7)\end{array}$ & $\begin{array}{l}27(90) \\
15(50) \\
27(90) \\
18(60) \\
27(90) \\
17(57) \\
13(43) \\
5(17)\end{array}$ \\
\hline
\end{tabular}

TABLE II-Cystometric values before and after treatment

\begin{tabular}{|c|c|c|c|}
\hline . & $\begin{array}{c}\text { Before } \\
\text { treatment }\end{array}$ & $\begin{array}{c}\text { After } \\
\text { flurbiprofen }\end{array}$ & $\begin{array}{c}\text { After } \\
\text { placebo }\end{array}$ \\
\hline $\begin{array}{l}\text { Residual volume (ml) } \\
\text { Volume causing first sensation ( } \ddot{m l} \text { ) } \\
\text { Bladder capacity (ml) ... } \\
\text { Detrusor-pressure rise (cm water) } \\
\text { No of patients with detrusor con- }\end{array}$ & $\begin{array}{r}29 \cdot 8 \\
174 \cdot 8 \\
403 \cdot 7 \\
45 \cdot 5\end{array}$ & $\begin{array}{r}27 \cdot 8 \\
221 \cdot 6 \\
468 \cdot 7 \\
37 \cdot 5\end{array}$ & $\begin{array}{r}15 \cdot 2 \\
195 \cdot 8 \\
448 \cdot 3 \\
46 \cdot 0\end{array}$ \\
\hline $\begin{array}{l}\text { tractions exceeding } 15 \mathrm{~cm} \text { water } \\
\text { No of patients with leaks }\end{array}$ & $\begin{array}{l}25 \\
19\end{array}$ & $\begin{array}{r}18 \\
7\end{array}$ & $\begin{array}{l}20 \\
16\end{array}$ \\
\hline
\end{tabular}


and five patients during the placebo period (table III). Two patients complained of more than one side effect while taking flurbiprofen.

Two urinary tract infections occurred. One was diagnosed and eradicated before the patient entered the trial, and the other was diagnosed after treatment with the first drug; the second patient was excluded from further study.

TABLE III-Numbers (percentages) of patients with side effects recorded during treatment*

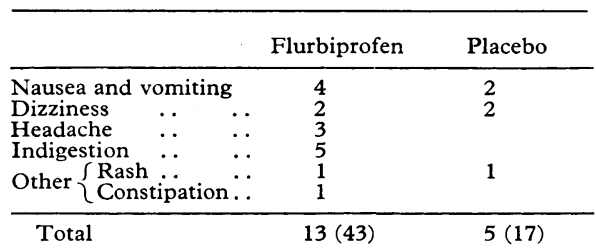

*Two patients had more than one side effect from flurbiprofen.

\section{STATISTICAL EVALUATION}

Symptoms-Flurbiprofen caused a highly significant reduction in both diurnal and nocturnal frequency as compared with placebo (Student's $t$ test: $P<0.001$ ). Urgency and urge incontinence were also significantly reduced by flurbiprofen (McNemar's test: $P<0.025$ ). Stress incontinence and enuresis, however, were not significantly altered.

Cystometric values-Flurbiprofen significantly reduced detrusorpressure rise during bladder filling as compared with placebo (Student's $t$ test: $P<0 \cdot 01$ ). Athough the volume of urine causing first sensation was significantly increased after flurbiprofen (Student's $t$ test: $P<0.05$ ), there was no significant change in bladder capacity. While taking flurbiprofen significantly fewer patients had leaks during cystometry (McNemar's test: $\mathrm{P}<0.025$ ).

Side effects-The incidence of side effects was significantly higher with flurbiprofen than with placebo (McNemar's test: $P<0.025)$.

\section{Discussion}

Double-blind, cross-over trials of drugs eliminate both the placebo factor and the doctor's bias in favour of the preparation in use. This is particularly important in disorders such as detrusor instability, which has a psychosomatic element and may remit spontaneously.

Although many drugs have been tried in detrusor instability, none has achieved universal success. ${ }^{9}$ The improvement in symptoms and cystometric values after flurbiprofen, however, were all significant, and 19 patients wished to continue with the drug.

Flurbiprofen is rapidly absorbed from the small intestine, and the peak serum concentration occurs at 90 minutes. Nevertheless, the rate of absorption is affected by fatty foods, and at present no parenteral preparation is available.

Thirteen patients $(43 \%)$ had side effects while taking flurbiprofen. The erythematous rash in one patient, however, was probably not caused by this drug, as it continued throughout the placebo period. No patient stopped treatment or reduced the dose because of side effects.

Twenty-seven patients had idiopathic detrusor instability, and the results reflect the changes in these. Of the three patients with multiple sclerosis, however, only one obtained significant relief. Symptoms of frequency (diurnal and nocturnal), urgency, and urge incontinence were all reduced, and she continued to take the drug after the trial. Her cystometric values, however, were virtually unaltered. Because of the invasive techniques used in this study the inclusion of more patients with neuropathic detrusor instability was thought to be unjustified.

In the idiopathic group the success or failure of flurbiprofen was not related to age or the duration of symptoms. Nor was there any difference between those exhibiting detrusor contractions and those with a steep rise in detrusor pressure. ${ }^{10}$
Flurbiprofen probably does not abolish abnormal detrusor activity but delays the pressure rise until intravesical distension is greater. This would explain the better improvement in symptoms than in cystometric values and also why there was a significant increase in bladder volume at first sensation though the actual capacity was not significantly altered. Future prostaglandin synthetase inhibitors may be more potent and therefore have more effect in detrusor instability. Because of the incidence of side effects with flurbiprofen $50 \mathrm{mg}$ thrice daily a higher dose would probably not be tolerated well enough for satisfactory evaluation.

LDC was funded by the Multiple Sclerosis Society. Boots Company Ltd funded HR and generously provided flurbiprofen and the placebo. We thank Dr B Marsh, of Boots Company Ltd, for helpful advice.

\section{References}

${ }^{1}$ Gilmore NJ, Vane JR. Hormones released into the circulation when the urinary bladder of the anaesthetised dog is distended. Clin Sci 1971;41 69-83.

2 Abrams PH, Feneley RCL. The action of prostaglandins on the smooth muscle of the human urinary tract, in vitro. $B r \mathcal{F}$ Urol 1976;47:909-15.

3 Bultitude MJ, Hills NH, Shuttleworth KED. Clinical and experimental studies on the action of prostaglandins and their synthesis inhibitors on detrusor muscle in vitro and in vivo. Br $\mathcal{F}$ Urol 1976;48:631-7.

4 Vane JR. Inhibition of prostaglandin synthesis: a mechanism of action for aspirin-like drugs. Nature [New Biol] $1971 ; 231: 232-5$.

5 Cardozo LD, Stanton SL. A comparison between bromocriptine and indomethacin in the treatment of detrusor instability. $\mathcal{F}$ Urol (in press)

${ }^{6}$ Crook D, Collins AJ, Bacon PA, Chan R. Prostaglandin synthetase activity from human rheumatoid synovial microsomes. Ann Rheum Dis 1976; 35:327-32.

${ }^{7}$ Lee P, Anderson JA, Miller J, Watson Buchanan W. Evaluation of analgesic action and efficacy of anti-rheumatic drugs. Rheumatology $1976 ; 3: 283-94$.

${ }^{8}$ Bates CP, Corney CE. Synchronous cine/pressure/flow cystography: a method of routine urodynamic investigation. Br 7 Radiol 1971;44:44-50.

${ }^{9}$ Cardozo LD, Stanton SL. Genuine stress incontinence and detrusor instability. Br $\mathcal{F}$ Obstet Gynaecol (in press).

${ }^{10}$ Cardozo LD, Stanton SL, Williams JE. Detrusor instability following surgery for genuine stress incontinence. Br F Urol 1979;51:204-7.

(Accepted 5 November 1979)

ONE HUNDRED YEARS AGO A propos of the Smithfield Cattle Show, and in a rather fantastic leader, the Times broaches a delicate though important subject by observing that, with a suitable dignity and even magnificence, there was last week exhibited in this metropolis the splendid and convincing illustration of a fact which has a high part in the course of this world. The virtue of breed, whether in man or in the creatures by which he is immediately surrounded, is maintained as the basis of our Constitution at Westminster, but appeals to our senses at Islington. It is found possible not only to produce cows and sheep and pigs that are models of perfection in their respective ways, but to reproduce them to almost any number with an approach to certainty. It is a trite comment, but continually enforced by fresh experience, that what we do with these poor beasts we can do with mankind. The moral of the Smithfield Club Show is invaluable in its application to the meritorious and necessary classes that do the work of this country, whether in country or in town, whether in the field or in the workshop and factory. If we can make beeves, sheep, and pigs yield the greatest possible quantity of the best possible meat, surely we can do something to make our labourers and artisans yield the most possible work with the least possible pain and injury to themselves. We all have our ideal of a British labourer or working man. But we are all painfully aware how few of the class fulfil the ideal. The present show demonstrates the possibility of improving a living breed up to a required perfection. Of course, there are special difficulties in the application of this process to reasonable beings with wills of their own and rights of their own. Yet much can be done, and much has to be done. Our population may be increasing, but it does not keep pace with the numerous drains upon it and our national requirements. (British Medical fournal, 1880.) 